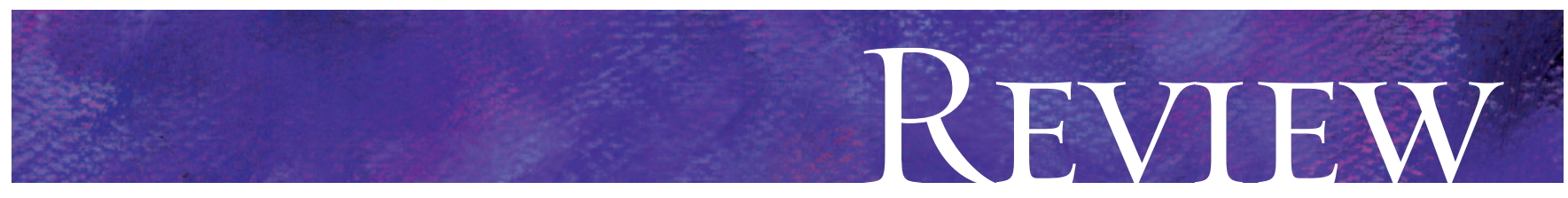

\title{
Sleep and aging: 1 . Sleep disorders commonly found in older people
}

\author{
Norman Wolkove, Osama Elkholy, Marc Baltzan, Mark Palayew
}

\section{ABSTRACT}

Aging is associated with several well-described changes in patterns of sleep. Typically, there is a phase advance in the normal circadian sleep cycle: older people tend to go to sleep earlier in the evening but also to wake earlier. They may also wake more frequently during the night and experience fragmented sleep. The prevalence of many sleep disorders increases with age. Insomnia, whether primary or secondary to coexistant illness or medication use, is very common among elderly people. Rapid eye movement (REM) sleep behaviour disorder and narcolepsy, although less common, are frequently not considered for this population. Periodic leg-movement disorder, a frequent cause of interrupted sleep, can be easily diagnosed with electromyography during nocturnal polysomnography. Restless legs syndrome, however, is diagnosed clinically. Snoring is a common sleeprelated respiratory disorder; so is obstructive sleep apnea, which is increasingly seen among older people and is significantly associated with cardio- and cerebrovascular disease as well as cognitive impairment.

CMAJ 2007;176(9):1299-304

S leep is a vital physiologic process with important restorative functions. Notable qualitative and quantitative changes in sleep occur with age. Moreover, many sleep-related disorders occur with increasing frequency among elderly people. These conditions are often not appreciated by physicians, the associated symptoms ascribed instead to coexistant medical illness. In part 1 of this review, we attempt to summarize several of the most important sleeprelated disorders commonly observed in older patients. In the forthcoming part 2, we will highlight the principles of treatment of these conditions.

\section{Age-related sleep changes}

Normal sleep progresses through several stages in a predictable fashion (Table I). This cycle repeats several times during the sleep period. With age, important changes in sleep structure occur (Box I) ${ }^{1}$ perhaps most characteristic is a phase advance of the normal circadian cycle. The result is a propensity toward an earlier sleep onset, accompanied by an earlier morning wake signal. Thus, elderly people often go to bed early and report being early risers. With aging, the total amount of time asleep shortens: infants and young children sleep an average of $16-20$ hours per day; adults, $7-8$; and people over 60 years of age, $6^{\mathrm{T}} / 2$ hours daily. ${ }^{2}$ Delta sleep (stages 3 and 4 ), the deepest and most refreshing form of sleep, diminishes with age. ${ }^{2}$

\section{Sleep pathologies in older patients}

\section{Insomnia}

Insomnia, defined as difficulty falling or staying asleep, is frequent in older people. ${ }^{1,2}$ In some patients, insomnia can be caused by an underlying medical condition or a medication side effect (secondary insomnia). In the absence of a causative factor, it is referred to as primary insomnia. Monane $^{3}$ has estimated that insomnia affects nearly half of all those over the age of 65 years. Elderly women tend to report sleep disturbances more frequently than elderly men. ${ }^{4}$ The sleep changes noted among older women may be partly related to changes in the postmenopausal profile of sex hormones. Estrogen deficiency in particular has been postulated to contribute to the sleep difficulties that women often begin to experience in their perimenopausal period, and then increasingly with age. ${ }^{5}$

Frequent awakenings are particularly common among elderly people and may be related to their more frequent incidences of concurrent medical conditions. Among the most common causes of secondary insomnia are a variety of musculoskeletal disorders, nocturia related to benign prostatic hypertrophy in men and bladder instability with decreased urethral resistance in women, congestive heart disease, and chronic obstructive lung disease.

Depression and anxiety disorders, common among people over 65 years of age, frequently contribute to insomnia. ${ }^{6}$ Risk factors for depression in older people include loss of a spouse, retirement, social isolation, comorbid disease and onset of dementia.

Sleep disturbance or disruption is common among patients experiencing dementia, particularly those with Alzheimer's disease. ${ }^{7}$ Such patients often have difficulty not only falling asleep but also with repeated nighttime awakenings. In general, as the dementia progresses, these symptoms become increasingly severe and patients become noticeably and progressively sleepier during the daytime. 
Table 1: The stages of sleep

\begin{tabular}{ll}
\hline Stage & \multicolumn{1}{c}{ Characteristics } \\
\hline Awake & - "Alert" brain \\
& - Muscles relatively tense \\
\hline Non-REM sleep & \\
\hline Stage 1 & - Transition stage \\
& - Light sleep \\
& - Reduced brain-wave activity \\
& - Slow eye movements \\
& - Muscle relaxation \\
Stage 2 & - Decreased body temperature \\
& - Reduced heart rate \\
& - Sleep spindles on electroencephalograph \\
& - Deep sleep \\
\hline Stages 3 and 4 & - High-voltage, low-frequency brain waves \\
(slow-wave sleep) & - Restorative sleep \\
& - Rapid eye movements \\
REM sleep & - Vivid dreaming \\
& - Increased brain activity \\
& - Increased heart rate \\
& - Active inhibition of voluntary muscles \\
\hline
\end{tabular}

Note: REM = rapid eye movement.

They may also exhibit recurrent agitated behaviour, known as "sundowning," during which these patients are more confused, disoriented, suspicious and restless. They may yell or exhibit violent behaviour, and are prone to wandering. Although episodes may occur at any hour, they are most common in late afternoon or evening - hence its descriptive term. For caregivers, this behaviour is extremely disruptive, and often becomes the ultimate reason for admission of a patient with dementia to an institution. Interestingly, McKibbon and colleagues ${ }^{8}$ also showed that elderly caregivers of patients with Alzheimer's disease reported more sleep problems and functional impairment from sleepiness than noncaregivers.

Insomnia is also common in people who have Parkinson's disease,${ }^{9}$ who may experience frequent awakenings with difficulty returning to sleep. They also frequently complain of vivid dreams, nightmares and leg jerks. Restless legs syndrome and rapid eye movement (REM)-sleep behaviour disorder, described following, may also affect these patients.

\section{Box 1: Typical sleep changes with aging}

- Decreased total nocturnal sleep time

- Delayed onset of sleep

- Advanced circadian phase: early to bed, early to rise

- Reduced slow-wave sleep

- Reduced rapid-eye-movement (REM) sleep

- Reduced threshold for arousal from sleep

- Fragmented sleep with multiple arousals

- Daytime napping
Table 2: Medications and other substances that can contribute to insomnia in older patients

\begin{tabular}{|c|c|}
\hline Substance & Effects and points of advice \\
\hline Alcohol & $\begin{array}{l}\text { Sleep induction } \\
\text { Subsequent sleep disruption }\end{array}$ \\
\hline $\begin{array}{l}\text { Anticholinesterase } \\
\text { inhibitors }\end{array}$ & $\begin{array}{l}\text { Insomnia } \\
\text { Disturbing dreams }\end{array}$ \\
\hline$\beta$-blockers & $\begin{array}{l}\text { Sleep physiology altered } \\
\text { Nightmares possible }\end{array}$ \\
\hline Caffeine, decongestants & $\begin{array}{l}\text { Stimulant effects } \\
\text { - Advise patient to avoid evening use }\end{array}$ \\
\hline Carbadopa, levadopa & Nightmares; insomnia \\
\hline Corticosteroids & $\begin{array}{l}\text { Stimulant effect; may cause agitation } \\
\text { - Prescribe lowest possible dose }\end{array}$ \\
\hline Diuretics & $\begin{array}{l}\text { Nocturia } \\
\text { - Avoid late in day }\end{array}$ \\
\hline Nicotine & - Encourage smoking cessation \\
\hline Phenytoin (e.g., Dilantin) & Frequent insomnia \\
\hline SSRIS & Frequent insomnia \\
\hline Theophylline & $\begin{array}{l}\text { Stimulant effect } \\
\text { - Substitute metered-dose broncho- } \\
\text { dilators }\end{array}$ \\
\hline Thyroid hormone & - Check thyroid function \\
\hline
\end{tabular}

Note: SSRIs = selective serotonin reuptake inhibitors.

Use of medication increases with age. Older, communitydwelling people commonly undergo polypharmacy and receive inappropriate prescriptions from physicians,${ }^{10}$ which unfortunately increases the possibility of insomnia related to medication use. A careful drug history is therefore imperative when an older patient with insomnia is assessed. Many drugs and other ingested substances have been shown to cause or contribute to insomnia; examples are presented in Table 2 . This is particularly important in elderly patients who may, for physiologic reasons, be more susceptible to the stimulatory effects of these agents. The stimulant effect of caffeine, for example, which can last 8-I4 hours, may be more pronounced in older people, especially when decreased liver function impairs caffeine clearance. Many older people use alcohol as a sleep aid, but even moderate consumption near bedtime can cause intense dreaming and nocturnal awakenings. These arousals appear to result from sympathetic stimulation and catecholamine release associated with the eventual fall of blood alcohol levels. Older people seem to be more sensitive to these effects.

\section{REM-sleep behaviour disorder}

Normally, dreaming occurs during REM sleep. Fortunately, during this phase of sleep the voluntary muscles are actively inhibited, which renders us incapable of "acting out" our dreams. REM-sleep behaviour disorder is characterized by the loss of this normal muscle atonia. Affected people may display a variety of movements, which in extreme cases can be harmful to the patient or bed partner. A patient may get up 
and walk about, thrash limbs, flail arms or legs, or even engage in complex activity such as eating, while remaining in REM sleep.

Nine out of ro patients with REM-sleep behaviour disorder are men. ${ }^{11,12}$ The disorder usually affects people older than $60 .{ }^{11,12}$ It is frequently associated with other neurodegenerative conditions such as Parkinson's disease, multiple sclerosis or Alzheimer's dementia. ${ }^{11,12}$ Interestingly, symptoms of REM-sleep behaviour disorder may precede a diagnosis of Parkinson's disease by years. ${ }^{13}$ Patients known to have Parkinson's have been found to have coexistant REM-sleep behaviour disorder in $15 \%-47 \%$ of cases. ${ }^{14}$ The progressive nature of this sleep disorder and its prevalence among older people and patients with Parkinsonian syndromes have led to speculation that idiopathic REM-sleep behaviour disorder is a neurodegenerative disorder of the deep nuclei and brainstem neurons involved in the integration of the sleep-wake cycle and the locomotor system. ${ }^{11-14}$

The diagnosis is made by history and supported by polysomnography: overnight multichannel monitoring in a sleep laboratory. In a Canadian study, Gagnon ${ }^{14}$ found that a third of patients with Parkinson's disease could be diagnosed with REM-sleep behaviour disorder according to polysomnographic criteria, when only half of those would have been detected through history alone. Because appropriate treatment of this disorder can be beneficial, accurate diagnosis is important. Moreover, Comella's group ${ }^{15}$ found that REM-sleep behaviour disorder was a frequent cause of sleep-related injuries of elderly patients with Parkinson's disease. Knowledge of its existence may prompt caregivers to ensure a safe and secure nocturnal environment.

\section{Narcolepsy}

A chronic neurologic disorder of unclear origin, narcolepsy results in excessive daytime somnolence and fatigue. ${ }^{16}$ The main symptoms of this condition are "sleep attacks," during which patients experience an irresistible urge to sleep (for a few minutes or up to an hour); hypnogogic hallucinations (extremely vivid auditory or visual hallucinations experienced while falling asleep or when waking up); sleep paralysis (a temporary inability to move upon wakening or before falling asleep); and cataplexy (a sudden, temporary, often unpredictable loss of muscle tone, which leads frequently to complete collapse).

Cataplexy can occur in the absence of other features of narcolepsy. Some attacks last up to half an hour, during which the patient is awake but unable to move or, in milder cases, experiences focal muscle weakness. Cataplexic episodes are sometimes triggered by intense emotion, including crying or laughing.

Although narcolepsy usually begins during the teen years or early twenties, symptoms tend to be lifelong. ${ }^{16}$ It may therefore be seen in older patients who have had the condition for many years. ${ }^{16}$ In others, mild disease severity, misdiagnosis or long delays in cataplexy expression may prevent proper diagnosis and treatment. ${ }^{17,18}$ Chakravete and $\mathrm{Rye}^{18} \mathrm{es}^{-}$ timated that it first comes to medical attention after the age of 40 years in nearly half of affected patients. Rye and associates $^{19}$ stressed that, during differential diagnosis, narcolepsy should always be considered by physicians faced with an older patient experiencing sleepiness or with transient loss of muscle tone.

Once suspected, narcolepsy is usually evaluated by documenting the presence and severity of daytime sleepiness by means of a multiple sleep-latency test. ${ }^{20}$ Polysomnography is essential to rule out other sleep disorders.

\section{Periodic leg movements and restless legs syndrome}

Sleep-related movement disorders are an often-overlooked cause of interrupted sleep and daytime sleepiness or fatigue among older patients.

Periodic leg movements represent a unique motor disorder, in that they occur specifically during sleep. The abnormal movements range from subtle contraction of the muscles of the ankles and toes to impressive flailing of the arms and legs. This syndrome is diagnosed with polysomnography by recording bursts of electromyographic activity that recur at regular periods in the affected muscles. Its prevalence increases with age; one study ${ }^{21}$ found the condition in $45 \%$ of a randomly selected sample of elderly subjects. The syndrome can be asymptomatic and require no intercession. Among older patients with insomnia, however, the finding of periodic leg movements warrants treatment.

Restless legs syndrome is a distinct entity sometimes confused with periodic leg-movement disorder (Table 3). Patients with restless legs complain of tingling, unpleasant, crampy or even very painful sensations, usually in their lower extremities. ${ }^{22}$ Often, they describe "a crawling feeling" under the skin. The condition is characterized by an intense urge to move or massage the legs, which offers some relief. Unlike periodic leg movements, which awaken people from sleep, the symptoms of restless legs syndrome usually occur when patients get into bed, and thereby cause sleep-onset insomnia.

Restless legs syndrome is common in older people, with an estimated prevalence of 10\%-35\% among those over 65 years of age. ${ }^{23}$ Unlike periodic leg-movement disorder, it has a female predominance. ${ }^{24}$ The majority of patients with restless legs also have periodic leg movements, but only about a quarter of patients with a diagnosis of periodic leg movements also have restless legs syndrome.

Although it can be idiopathic, restless legs syndrome can also be associated with iron deficiency, rheumatoid arthritis, renal failure and a variety of neurologic lesions, especially peripheral neuropathy..$^{25}$ About half of patients with the syndrome have a positive family history, which suggests an underlying genetic predisposition as yet poorly defined. ${ }^{25}$

The pathogenesis of restless legs syndrome is unclear, but appears to involve abnormalities in dopaminergic neural transmission or iron metabolism. ${ }^{23-25}$ There is evidence for age-related dysfunction of the descending dopaminergic pathways, possibly originating in the diencephalon or upper brainstem. ${ }^{26}$ In fact, L-dopa or dopamine agonist administration can decrease the symptoms of restless legs syndrome. ${ }^{25}$ 


\section{Sleep-related respiratory disorders}

These disorders include several conditions that range from snoring to hypopneas and apneas during sleep.

\section{Snoring}

Common in the general population, snoring is a frequent complaint of older people. With aging, the apparent weakening and loss of tone of upper airway muscles during sleep predisposes to airway obstruction that leads to snoring. Its prevalence and relation to age is difficult to define because studies have differed in methodology, some using objective measures and others relying on subjective reports. As a result, the prevalence rates found have varied widely. Dealberto and coworkers ${ }^{27}$ found that almost $60 \%$ of a sample of people aged $60-70$ years in Nantes, France reported snoring. In the large Cardiovascular Health Study, ${ }^{28}$ which included over 5000 people aged 65 years and older, $33 \%$ of men and $19 \%$ of women self-reported "loud" snoring. In that study the prevalence of snoring was actually noted to fall after the age of 75 . Linburg and coinvestigators ${ }^{29}$ similarly found that the prevalence of snoring in men increased (peaking, in their study, at 50-60 years of age) and subsequently decreased. The apparent decline in the incidence of snoring in the oldest cohorts could reflect a survivorship effect, if snoring is in fact related to other diseases and, ultimately, deaths among older people.

There has been a debate in the literature about the clinical significance of snoring. One school of thought holds that, even without associated obstructive sleep apnea, the upper airway narrowing that produces snoring is itself sufficient to have important medical consequences, especially in older people, and may predict hypertension, ischemic heart disease, stroke and overall rates of death..$^{30-32}$ Leineweber and coauthors ${ }^{32}$ for example, concluded that snoring actually contributes to the atherosclerotic process in patients with cardiac disease. Others argue that snoring is merely associated with, or a marker of, other conditions that are themselves predictors of illness and death, such as obesity. ${ }^{35}$ Jennum and associates $^{34}$ stressed that the link between snoring and cardiovascular disease is explainable by the formers' association with known risk factors for the disease. In a follow-up study, ${ }^{35}$ they concluded after multivariate adjustments that snoring was not independently associated with ischemic heart disease.

\section{Obstructive sleep apnea}

In this important respiratory disorder, the upper airway is repeatedly obstructed during sleep, which reduces air flow (hypopnea) or stops it (apnea). The site of obstruction is usually the base of the tongue and palate. During sleep the pharyngeal muscles relax, and the tongue and palate fall backward, obstructing the airway. These episodes lead to interrupted, poor-quality sleep, nocturnal oxygen desaturation, and a notable reduction or even complete absence of REM sleep. The average number of apneas and hypopneas per hour is the apnea-hypopnea index, a useful gauge of the severity of this condition.

Patients with obstructive sleep apnea are more often male and are frequently, but not necessarily, obese. They may deny having any problem with sleep and come to medical attention only because a bed partner has noted loud snoring (the preobstructive phase) punctuated by silences of varying

Table 3: Characteristics of sleep-related movement disorders - restless legs and periodic leg movements

\begin{tabular}{|c|c|c|c|c|}
\hline Aspect & \multicolumn{2}{|c|}{ Restless legs syndrome } & \multicolumn{2}{|c|}{ Periodic leg-movement disorder } \\
\hline $\begin{array}{l}\text { Clinical } \\
\text { features }\end{array}$ & \multicolumn{2}{|c|}{$\begin{array}{l}\text { - Unpleasant sensations in legs, usually at night } \\
\text { - Described as “creeping," "crawling" or painful } \\
\text { - Improved by movement } \\
\text { - Sleep-onset insomnia } \\
\text { - Daytime fatigue }\end{array}$} & \multicolumn{2}{|c|}{$\begin{array}{l}\text { - Involuntary limb movements that recur at regular intervals } \\
\text { (20-40 s) during the non-rapid-eye-movement stages of sleep } \\
\text { - Patient often unaware of movements } \\
\text { - Frequent arousal or awakening during sleep } \\
\text { - Daytime fatigue }\end{array}$} \\
\hline Prevalence & \multicolumn{2}{|c|}{$\begin{array}{l}\text { - } 2 \%-15 \% \text { of general population } \\
\text { - } 10 \%-35 \% \text { among people } 65 \text { years or older } \\
\text { - More common in women than in men }\end{array}$} & \multicolumn{2}{|c|}{$\begin{array}{l}\text { - } 5 \% \text { among people aged } 30-50 \mathrm{yr} \text {; up to } 45 \% \text { among those } \geq 65 \mathrm{yr} \\
\text { - Equally common in women and men }\end{array}$} \\
\hline Diagnosis & \multicolumn{2}{|l|}{ Clinical } & \multicolumn{2}{|c|}{ Polysomnography showing repetitive muscle contractions } \\
\hline $\begin{array}{l}\text { Associated } \\
\text { factors }\end{array}$ & $\begin{array}{l}\text { - Accompanied by periodi } \\
\text { in about } 85 \% \text { of cases } \\
\text { - Family history (about ha } \\
\text { More common } \\
\text { - Iron deficiency } \\
\text { - Peripheral neuropathy } \\
\text { - Renal failure }\end{array}$ & $\begin{array}{l}\text { leg-movement disorder } \\
\text { Lef of affected people) } \\
\text { Less common } \\
\text { - Diabetes } \\
\text { - Parkinson's disease } \\
\text { - Cigarette smoking } \\
\text { - Use of alcohol, caffeine } \\
\text { - Some medications }\end{array}$ & \multicolumn{2}{|c|}{ Accompanied by restless legs syndrome in around $25 \%$ of cases } \\
\hline Treatments & $\begin{array}{l}\text { In frequent use } \\
\text { - Dopaminergic agents } \\
\text { - Dopamine agonists }\end{array}$ & $\begin{array}{l}\text { Less frequently used } \\
\text { - Benzodiazepines } \\
\text { - Anticonvulsants } \\
\text { - Opioids }\end{array}$ & $\begin{array}{l}\text { In frequent use } \\
\text { - Dopaminergic agents } \\
\text { - Dopamine agonists }\end{array}$ & $\begin{array}{l}\text { Less frequently used } \\
\text { - Benzodiazepines } \\
\text { - Anticonvulsants } \\
\text { - Muscle relaxants }\end{array}$ \\
\hline
\end{tabular}


length (the obstructive apnea phase). Others may complain of severe fatigue or be observed to be excessively drowsy during the daytime.

Those with documented obstructive sleep apnea and daytime sleepiness are said to have obstructive sleep apnea syndrome, which is common in the general population. This syndrome is even more frequent among older people, especially those who complain specifically of daytime fatigue. ${ }^{36}$ It occurs in at least $4 \%$ of men and $2 \%$ of women aged $30-$ 60 years. ${ }^{37}$ Among those over 60 years of age, prevalence rates as high as $45 \%-62 \%$ have been quoted. ${ }^{38}$ Groth $^{39}$ moreover suggests that people with sleep apnea who are older are less likely to seek medical attention. ${ }^{39}$ The syndrome may not be recognized in older patients because its symptoms (fatigue, somnolence and morning headache) are ascribed to other diseases, or to aging, itself.

Several authors have sought to explain the increased prevalence of this condition among older people. Certainly the increased occurrence of obesity, which predisposes to upper airway narrowing, is a factor. Age-related decline in muscle tone, which enhances upper-airway collapsibility, is another. ${ }^{40}$ Impaired pharyngeal sensory discrimination in older subjects also makes them more vulnerable to the occurrence and persistence of airway collapse during sleep..$^{41}$

Epidemiological studies have suggested a relation of obstructive sleep apnea to hypertension, stroke and ischemic heart disease. ${ }^{42}$ These are thought to result, at least in part, from frequent intense sympathetic stimulation that occurs at the end of each obstructive phase. This type of sleep apnea is also associated with the release of proinflammatory and prothrombotic factors important in the development of atherosclerosis. ${ }^{43}$

An important concept, especially for those who care for elderly people, is the notion that obstructive sleep apnea can contribute to cognitive impairment, which is likely related to frequent oxygen desaturation. Janssens and coinvestigators ${ }^{44}$ have even suggested that sleep-disordered breathing be considered during differential diagnosis of reversible dementia in older patients.

\section{Central sleep apnea}

This type of sleep apnea occurs in the absence of airway obstruction. It is thought to be caused by a periodic cessation of respiratory drive. Older patients who have had ischemic events involving the central nervous system may display frequent central sleep apnea with clinically significant nighttime oxygen desaturation. ${ }^{44}$

A distinctve form of central apnea is Cheyne-Stokes respiration: it has a characteristic cyclic pattern of waxing and waning breaths with periods of complete cessation of breathing. ${ }^{45}$ Cheyne-Stokes respiration is often seen in patients experiencing congestive heart failure. ${ }^{45}$

\section{Summary and conclusions}

Most practising physicians are seeing increasing numbers of elderly patients. It is important to know how sleep pat- terns change as we age, and to recognize that sleep disorders are common among older people. We have attempted to summarize the salient features of those seen most frequently in clinical practice. In the second part of our review on sleep and aging, we will highlight the management of these conditions.

This article has been peer reviewed.

From the Sleep Clinic, Mount Sinai Hospital Center, and the Department of Medicine, McGill University, Montréal, Que.

Competing interests: None declared.

Contributors: Norman Wolkove formulated the structure of the article. Osama Elkholy wrote the rough draft, and gathered information for the literature review. All authors contributed content, made critical revisions, and have seen and approved the final version for publication.

Acknowledgements: We thank Nathalie Bendavid and Karen Kennedy for assistance in the preparation of the manuscript.

\section{REFERENCES}

I. Neubauer DN. Sleep problems in the elderly. Am Fam Physician 1999;59:2551-6o.

2. Rajput V, Bromley SM.,Chronic insomnia: a practical review. Am Fam Physician I999;60:I43I-8. Discussion: I44I-2.

3. Monane M. Insomnia in the elderly. J Clin Psychiatry I992;53(Suppl):23-8.

4. Vitiello MV, Larsen LH, Moe KE. Age-related sleep change: gender and estrogen effects on the subjective-objective sleep quality relationships of healthy, noncomplaining older men and women. J Psychosom Res 2004;56:503-10.

5. Moe KE. Reproductive hormones, aging, and sleep. Semin Reprod Endocrinol I999;17:339-48.

6. Birrer RB, Vemuri SP. Depression in later life: a diagnostic and therapeutic challenge. Am Fam Physician 2004;69:2375-82.

7. Tractenberg RE, Singer CM, Kaye JA. Symptoms of sleep disturbance in persons with Alzheimer's disease and the normal elderly. J Sleep Res 2005;I4:177-85.

8. McKibbin CL, Ancoli-Israel S, Dimsdale J, et al. Sleep in spousal caregivers of people with Alzheimer's disease. Sleep 2005;28:1245-50.

9. Brotini S, Gigli GL. Epidemiology and clinical features of sleep disorders in extrapyramidal disease. Sleep Med 2004;5:169-79.

Io. Willcox SM, Himmelstein DU, Woolhandler S. Inappropriate drug prescribing for the community-dwelling elderly. JAMA 1994;272:292-6.

II. Sforza E, Krieger J, Petiau C. REM sleep behavior disorder: clinical and physiopathological findings. Sleep Med Rev I997;1:57-69.

I2. Olson EJ, Boeve BF, Silber MH. Rapid eye movement sleep behaviour disorder: demographic, clinical and laboratory findings in 93 cases. Brain 2000;123:33I-9.

13. Lai YY, Siegel JM. Physiological and anatomical link between Parkinson-like disease and REM sleep behaviour disorder. Mol Neurobiol 2003;27:137-52.

I4. Gagnon JF, Bedard MA, Fantini ML, et al. REM sleep behavior disorder and REM sleep without atonia in Parkinson's disease. Neurology 2002;59:585-9.

I5. Comella CL, Nardine TM, Diederich NJ, et al. Sleep-related violence, injury, and REM sleep behavior disorder in Parkinson's disease. Neurology I998;51:526-9.

I6. Chaudhary BA, Husain I. Narcolepsy. J Fam Pract 1993;36:207-13.

I7. Kelly JF, Lowe DC, Taggart HM. Narcolepsy in the elderly: a forgotten diagnosis. Age Ageing 1987;16:405-8.

I8. Chakravorty SS, Rye DB. Narcolepsy in the older adult: epidemiology, diagnosis and management. Drugs Aging 2003;20:36I-76.

19. Rye DB, Dihenia B, Weissman JD, et al. Presentation of narcolepsy after 40. Neurology $1998 ; 50: 459-65$.

20. Rack M, Davis J, Roffwarg HP, et al. The multiple sleep latency test in the diagnosis of narcolepsy [author reply: 2199]. Am J Psychiatry 2005;I62:2198-9.

2I. Ancoli-Israel S, Kripke DF, Klauber MR, et al. Periodic limb movements in sleep in community-dwelling elderly. Sleep I99I;I4:496-500.

22. Hickey J. Restless legs syndrome. Can Fam Physician 2000;46:1762-3.

23. Milligan SA, Chesson AL. Restless legs syndrome in the older adult: diagnosis and management. Drugs Aging 2002;19:74I-5I.

24. Rothdach AJ, Trenkwalder C, Haberstock J, et al. Prevalence and risk factors of RLS in an elderly population: the MEMO study. Memory and morbidity in Augsburg elderly. Neurology 2000;54:1064-8.

25. Sonka K, Kemlink D. Restless legs syndrome in 2004. Prague Med Rep 2004;105: 337-56.

26. Glasauer FE. Restless legs syndrome. Spinal Cord 200I;39:125-33.

27. Dealberto MJ, Pajot N, Courbon D, et al. Breathing disorders during sleep and cognitive performance in an older community sample: the EVA study. J Am Geriatr Soc 1996;44:1287-94.

28. Enright PL, Newman AB, Wahl PW, et al. Prevalence and correlates of snoring and observed apneas in 520I older adults. Sleep 1996;19:531-8. 
29. Lindberg E, Taube A, Janson C, et al. A ro-year follow-up of snoring in men. Chest I998;II4:IO48-55.

30. Koskenvuo M, Kaprio J, Telakivi T, et al. Snoring as a risk factor for ischaemic heart disease and stroke in men. Br Med J (Clin Res Ed) I987;294:16-9.

3I. Zamarron C, Gude F, Otero Otero Y, et al. Snoring and myocardial infarction: a 4year follow-up study. Respir Med I999;93:I08-I2.

32. Leineweber C, Kecklund G, Janszky I, et al. Snoring and progression of coronary artery disease: the Stockholm Female Coronary Angiography Study. Sleep 2004;27: I344-9.

33. Davies DP, Rodgers $\mathrm{H}$, Walshaw D, et al. Snoring, daytime sleepiness and stroke: a case-control study of first-ever stroke. J Sleep Res 2003;12:313-8.

34. Jennum P, Hein HO, Suadicani P, et al. Cardiovascular risk factors in snorers. A cross-sectional study of 3323 men aged 54 to 74 years: the Copenhagen Male Study. Chest I992;102:137I-6.

35. Jennum P, Hein HO, Suadicani P, et al. Risk of ischemic heart disease in selfreported snorers. A prospective study of 2937 men aged 54 to 74 years: the Copenhagen Male Study. Chest 1995;108:138-42.

36. Bailes S, Baltzan M, Alapin I, et al. Diagnostic indicators of sleep apnea in older women and men: a prospective study. JPsychosom Res 2005;59:365-73.

37. Young T, Palta M, Dempsey J, et al. The occurrence of sleep-disordered breathing among middle-aged adults. N Engl J Med i993;328:1230-5.

38. Ancoli-Israel S, Aayalon L. Diagnosis and treatment of sleep disorders in older adults. Am J Geriatr Psychiatry 2006;14:95-103.

39. Groth M. Sleep apnea in the elderly. Clin Geriatr Med 2005;2I:70I-I2

40. Crow HC, Ship JA. Tongue strength and endurance in different aged individuals. $J$ Gerontol A Biol Sci Med Sci 1996;51:M247-50.

4I. Aviv JE, Martin JH, Jones ME, et al. Age-related changes in pharyngeal and supraglottic sensation. Ann Otol Rhinol Laryngol I994;103:749-52.

42. Shamsuzzaman AS, Gersh BJ, Somers VK. Obstructive sleep apnea: implications for cardiac and vascular disease. JAMA 2003;290:1906-I4.

43. Parish JM, Somers VK. Obstructive sleep apnea and cardiovascular disease. Mayo Clin Proc 2004;79:1036-46.

44. Janssens JP, Pautex S, Hilleret H, et al. Sleep disordered breathing in the elderly. Aging (Milano) 2000;12:417-29.

45. Cherniack NS, Longobardo G, Evangelista CJ. Causes of Cheyne-Stokes respiration. Neurocrit Care 2005;3:27I-9.

Correspondence to: Dr. Norman Wolkove, Mount Sinai Hospital Center, 5690 Cavendish Blvd., Montréal QC $\mathrm{H}_{4} \mathrm{~W}_{\mathrm{I}} \mathrm{S}_{7}$; fax $5 \mathrm{I4}$

369-2225; norluco@yahoo.com

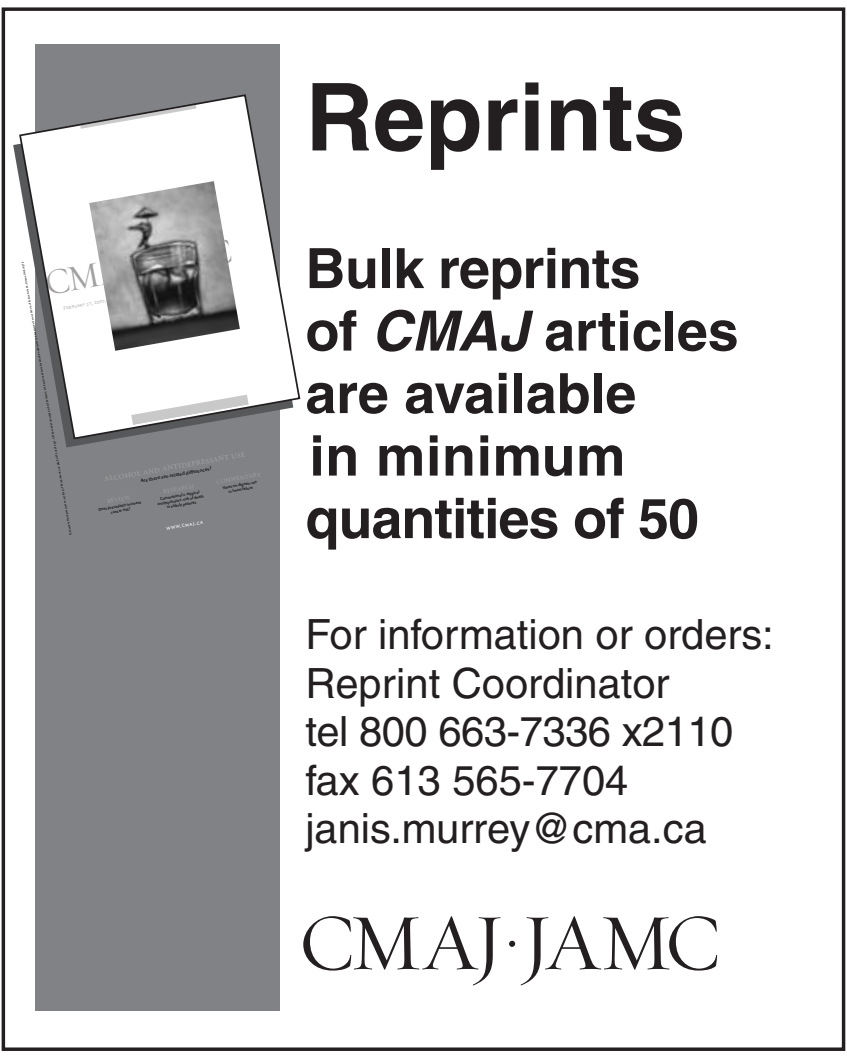

